"Among the drawbacks that may be specially named is the ignorance of legislators, of executives, and electors on this subject."

With this English readers will entirely concur. The next subject proposed as a definite object of study is that of economic entomology. Such enemies as the Colorado beetle, the wheat midge, the turnip fly, the wire worm, or the locust are among the most formidable which the farmer has to contend with. The depredations of the wheat midge alone may be appraised at over 3,000,000 bushels annually in Great Britain. Our Royal Agricultural Society has taken up this matter, and Miss Ormerod's book upon injurious insects is full of information and suggestions concerning it. This certainly is a branch of knowledge which requires labourers. From it we are led to reflect upon the important bearing of the study of entozoa upon agriculture, and especially upon the pathology of farm stock. The improvement of the American pastures appears to be desirable. According to Prof, Beal, a dozen sorts of grasses probably cover nineteen-twentieths of all the cultivated meadow-land from Maine to Texas. As the grass family is large, containing from 3100 to 4000 or more species, it is naturally thought that a few more might be found suitable for various parts of this immense area.

Not only is much to be done in the introduction of new grasses but in selecting and propagating varieties of the same grass. "Plants of red clover vary amazingly in many respects." "I believe- our fields of red clover today contain nearly or quite as great a variety of plants as would a field of Indian corn, if we were to mix in a little seed of all the varieties cultivated in any one "State." This is startling, but quite in accord with the wonderful variations observable in plants of Italian and perennial rye grass and other grasses and clovers. Thus Prof. Beal indicates various paths for improvement, and urges the vast importance of agricultural experiment stations, where work bearing upon the various subjects enumerated may be carried on by competent persons. There is nothing very new in all this. The importance of agricultural research has been often declared in our own country from the days of Sir Humphry Davy until now; but too often the voice has been as of one crying in the wilderness. Some good has been done, and we may expect a more rapid development of these ideas ere long. Scientific agriculture was never more popular than at present, and the number of agricultural students attending systematic courses of instruction is greater now than at any previous time. Agriculture has become a recognised subject of the Science and Art Department, and we note a disposition on the part of scientific men to attach greater importance to the study of domesticated animals and cultivated plants than formerly. We owe much of this to Darwin. He, more than any other man, raised the scientific interest of these humbler subjects of zoological and botanical science, which had previously been passed by scientific men with scarce concealed contempt. Anthropology has also done much to throw a halo of interest around those animals and plants which have been associated for long ages with man. Hence there is a greater bond of union between the present generation of scientific men and the agriculturist than existed a generation since, and it is probable that this sympathy will increase and fructify for the benefit of all.

IOHN WRIGHTSON

College of Agriculture, Downton, Salisbury

\section{THE GREAT NEBULA IN ORION}

$\mathrm{T}$ is a fortunate circumstance for students of nebular astronomy that within a short time that branch of science has been enriched by a monograph and a photograph, each perfect in its way, of one of the grandest objects in the heavens. The monograph is from the pen of Prof. Holden, ${ }^{1}$ whose name is a guarantee of thoroughness; the photograph we owe to $\mathrm{Mr}$. Common, who at one bound has distanced all predecessors, and has shown us that in the future we may hope for permanent records of the nebula as perfect as those of the surfaces of the sun and moon produced by Janssen and Rutherfurd.

In the present article we propose to refer to both these productions with a view of showing how terribly physical astronomers are losing time in not throwing all their energies in to the production of photographic records whenever possible. In Prof. Holden's paper we are enabled to see how, two hundred years ago, time was lost and false issues raised because the astronomers of those days had never learned to draw ; indeed it is terrible to look at the collection of rude, crude, and alm ost impossible sketches by Huyghens, Mairan, Picard, Long, Le Gentil, and others which he has brought together. Mr. Common on his part has shown us that it is possible to photograph, with about half an hour's exposure, all the details shown in the most careful drawings made by men with artistic training as the result of months-and we may almost say years-of labour; such drawings as we owe to Bond, Hersehel, and Lord Rosse. Mr. Common's photograph, it should also be said, includes the whole nebula, while the monograph is confined to the central portions.

The most convincing argument, however, in favour of the more serious employment of photography in our observatories, that we can use is to show the relation of the photograph to the memoir. The latter commences as follows :- "The main object of this memoir is to leave such measures and descriptions of the brightest parts of the nebula of Orion as shall enable another person observing in after years with the same telescope, under like conditions, to say with certainty whether or no changes have occurred in those parts of this nebula."

To carry out this object everything touching the nebula written between 1618 , when Cysat of Lucerne discovered it, and Holden's own observations of $188 \mathrm{I}$ has been brought together and coordinated, and the labour and time this has required may be gathered from the fact that the list of the more important papers relating to the nebula consulted in writing the memoir cover four pages quarto and includes about two hundred entries.

Now it is not too much to say that in the case of an astronomer taking up the question a century hence, as Prof. Holden has now done, he would prefer the single photograph taken by Mr. Common in thirty-seven minutes to all the literature so adinirably brought together by Prof. Holden; and if the world must in the meantime lose either the memoir and the records of the human effort of $2 \frac{1}{2}$ centuries on which it is based, or the photograph, then it is to be hoped that the photograph will be spared. We say this the more readily because we are certain that Prof. Holden will agree with us.

But it is time that we should refer to the memoir separately. It is preceded by Bond's magnificent drawing, I 859.63 , and an index chart giving the minute system of nomenclature necessarily adopted to distinguish the various bright masses, dark channels, spirals, \&c., of the portion under notice. The nomenclature is that of Sir John Herschel, Lord Rosse, and Liaponoff in the case of the nebula proper, while the stars are laid down from Bond's catalogue. The index map is indeed the only part of the memoir with which we have any fault to find, for it attempts too much, and for that reason will be of restricted use to those whose optical power is not of the greatest.

The drawings and memoirs are considered in chronological order; the woodcuts bring up the drawings to the same scale, or nearly so. We have the woodcut first, and then extracts of the ipsissima verba of the observations. Everything touching the central portion is given

" "Washington Astrunomical and Meteorological Observations," vol. $x x v ., 1878$. Published 1882 . 
fully, generally in the words of the author, including discussions as well as original observation; so, as the author points out, the admirable résumés of Liaponoff, Struve, D'Arrest, and others are available for immediate reference.

Although Cysat of Lucerne discovered the nebula, it was not the first discovered, that in Andromeda having been noticed by Abdul Rabman al Sûfi, A.D. 950, nor were Cysat's observations of much value. The observational work really dates from 1656 , when Huyghens in dependently observed it, and recorded roughly, as we have said, its shape and the included stars. After all we must not be too hard on the early observers, for, according to
Arago, Huyghens' telescopes of $2 \frac{1}{3}$ inches diameter were 12 and 23 feet long, power 48 ; drawing at the telescope, therefore, was almost out of the question. This notable observation did not long escape our own keen-eyed Hooke, who added to the triad of stars in the central part of the nebula two others, and henceforward the little stellar group has been called the "trapezium," and is a test objert dear to all amateurs. Hooke's telescope was 36 feet long, aperture $3 \frac{1}{2}$ inches. Huyghens, in his later observation (1694), also caught the fourth star.

After this time the nebula and the number of its included stars grew and grew with every increase of optical power.

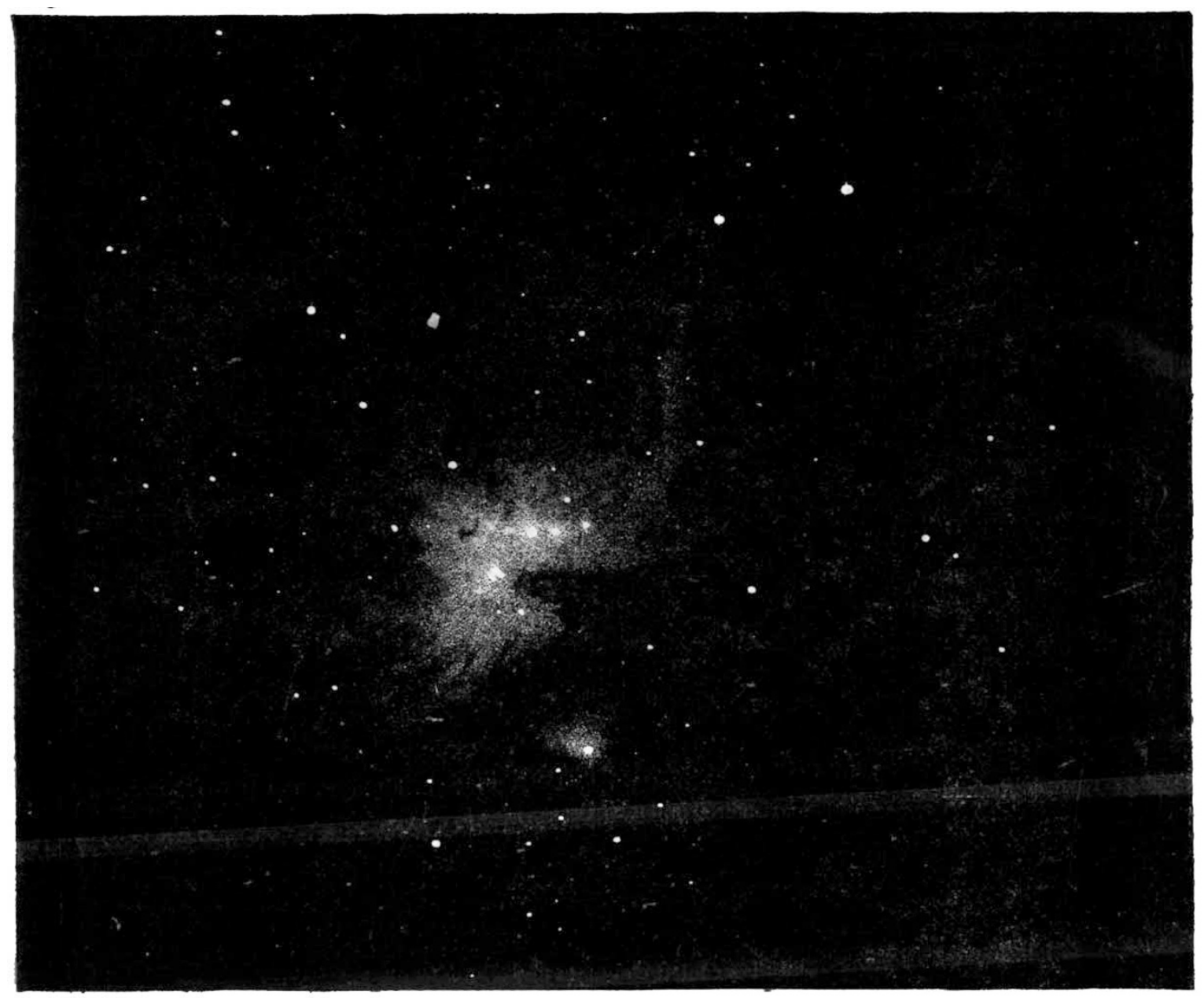

FIG. I. - The Great Nebula in Orion (from a photograph by Mr. A.A. Common).

The observations of Mairan (1731), Long (1742), Le Gentil (I758), Messier (177I), and Sir Wm. Hershel (1744-18II) follow next, the latter especially giving considerable attention to the nebula with his gigantic reflectors; and indeed it may be said he was the first to seriously study it, and among the results of his observation was the statement that the nebula had undergone changes during the time he had been studying it. The three points insisted upon by Herschel are carefully dis. cu ised by Holden, with the result that he considers none of them to be established.

Interpolated between the observations of Sir Wm. Herschel and his son (I824) are those of Schrœeter
(1794-98), Lefebvre (1799), Bode (1800), and Flaugergues ( 1802 ).

In Sir John Herschel's first memoir the accepted nomenclature is established; this is partly shown in the annexed sketch.

Like his father Sir John Herschel discussed the ques. tion of change. "To the reader who has never viewed this object through powerful telescopes, but who is familiar with the various representations which have from time to time been made of it (including my own of 1824), the number and complexity of the various branches and convolutions now first exhibited, and the different aspects under which the portions best known 
are now presented, will no doubt tend to convey a strong impression of great and rapid changes undergone by the nebula itself. I am far from participating in any such impression. Comparing only my own drawings made at epochs (1824 and 1837) differing by thirteen years, the disagreements, though confessedly great, are not more than I am disposed to attribute to inexperience in such delineations (which are really difficult) at an early period - to the far greater care, pains, and time bestowed upon the later drawings. . . . Now there is only one particular on which I am at all inclined to insist as evidence of change, viz., in respect of the situation and form of the nebula oblongata, which my figure of 1824 represents as a tolerably regular oval. . . . No observer now, I think, looking ever so cursorily at this point of detail, would represent the broken, curved, and unsymmetrical nebula in question ... as it is represented in the earlier of the two figures."

The enormous body of work done even in Sir J. Herschel's time, chiefly by Lassell, Bond, Liaponoff, Struve, and Lord Rosse, is so fully recorded that it is impossible to do more than refer to it in the space at our disposal, besides which much of it is so recent as to be still in the minds of all interested in such questions. But

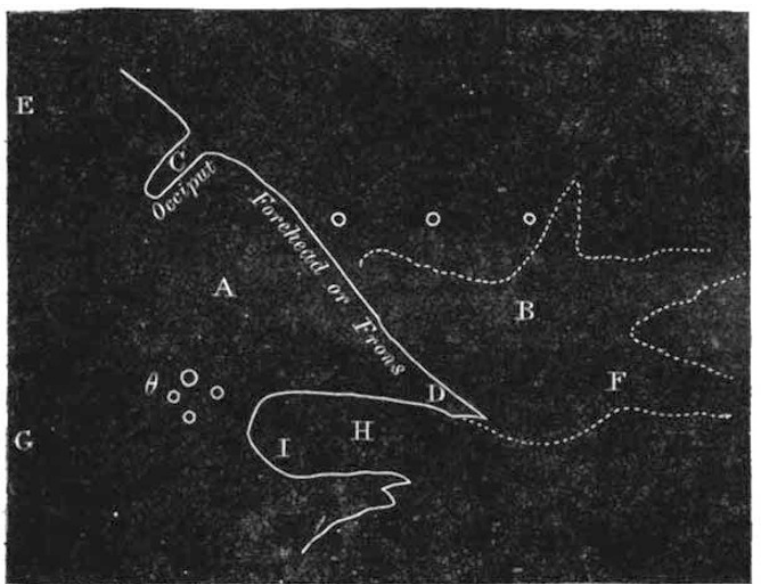

IIG. 2:- Sketch Map of the Huyghenan Regicn.-A, the Huyghenia (brightest) region; $\theta$, the four stars of the Trapezium; $B$, subnebulou region; C, Sinus Gentilii ; D, Rostrum ; E, Regio Gentiliana ; F Regio Messieriana-Brachium Messieri, Proboscis Major; G, Regio Derhemiana; H, Sinus Magnus; I, Schrœeter's Bridge.

Mr. Holden, in his work on the nebula, has not contented bimself with discussing this work merely. The Washington observations made by himself are given, and cover nearly Ios pages.

We may now deal with the results arrived at. Prof. Holden considers the evidence of change undoubted, but such change depends less upon actual change of form than upon shiftings of the maxima of brightness. The most undoubted changes are in the brightness of the first and second Schroter's bridge, and in the appearance of the nucleus of the first. The changes in the brightness of some of the masses are established by the Washington observations alone. Among the results of these observations is a new nebulous patch seen from the time of its origin, when it was stellar in appearance, and faint, until now, when it is bright, and of measurable dimensions.

Another matter investigated by Prof. Holden is the question of the connection of the stars with the nebula. On this point spectroscopic work is brought upon the scene. The spectrum of the nebula was first studied by Huggins. The gaseous nature of some of the small stars near the trapezium is, Prof. Holden thinks, indicated by their peculiar behaviour under different magnifying powers; some of them are best seen with low powers.
The question of photography is introduced in an appendix giving the results obtained by the late Dr. Draper just before bis lamented death. This photograph was exposed for 137 minutes, and, as may be easily imagined, lacks sharpness, but still, as Prof. Holden puts it, it worthily inaugurated nebular-photography. He also clearly pointed out that, since the eye and the salts of silver do not most strongly respond to light of the same wavelengths, the intensities of drawings and photographs must vary, and he shows that they do vary. On the other hand, it is shown that the untouched photograph defends the best drawings against the charge of depending too much upon the personal equation of the observer, as over large regions the best drawings are justified by the photograph.

Mr. Common's photograph, a reproduction of which we give, is far finer than Dr. Draper's, among other reasons because it was exposed for about one-third the time. It is to be hoped that we shall have photographs as good as this taken for the future every year, not only on plates responding to blue light, but on plates responding to green and red. In this way most precious records will be secured for future discussion.

On this question we may make the following quotationfrom Mr. Common's communication to the Royal Astronomical Society:-

"To find if there is any change of form or relative brightness observable in a nebula with any degree of certainty, it will be necessary to compare photographs taken at some undetermined interval of time; and the best thing to do now seems to me to be to get as many photographs as possible to form the basis of comparison with those taken at some future time; and this I am now doing.

"The light of this nebula is so different in intensity that for a proper exposure of the outer portions the central part is much over-exposed ; it is therefore necessary to take photographs with different exposures. Thus an exposure of from one to three minutes gives the brighter portions of the central parts in such a way that they can be easily compared and their order noted;"longer exposures giving portions less bright in a similar way, till, with a maximum exposure, the very faintest portions can be compared and noted in order. . The stars in the nebula can be treated in the same way, the same photographs being available."

We have before referred to the fact that many of the stars in and about the nebula are variable, particularly the faint ones. Mr. Common has found that one of the brighter stars is remarkably variable, though what its period is he has not yet determined

As the time of exposure can be easily extended to hours, it will evidently in the not distant future be easy to get stars invisible to the eye in the same telescope used for photography.

\section{NOTES}

AMONG the gold medals awarded by the juries of the International Fisheries Exhibition are the following in the department of Natural History :-INVERTEBRATA.--United Kingdom : James Cook, the Duke of Edinburgh, Prof. McIntosh, Thos. Bolton. Italy: Dr. Dohrn (2). Netherlands: Netherlands Zoological Society. United States: United States Fish Commission. New South Wales: Sydney Museum. Sweden : F. B. Wittrock, Baron Nordenskjöld, W. Lilljeborg. Russia : Dr. Oscar Grimm. Fish, \&c.-United States: United States National Museum, United States Fish Commission, Prof. Alexr. Agassiz, Prof. G. Brown-Goode, Prof. David S. Jordan. New South Wales: Australian Museum, Sydney (2); New South Wales Commission, Hun. W. Mackay, E. P. Ramsay. Sweden: the Royal Swedish Academy, Dr. Oscar Dickson. Carada: Canadian Government. China: Government of 